\author{
Central Queensland University, Australian Catholic University and University of \\ Technology Sydney
}

\author{
Donna Lee Brien, Alison Owens, Craig Batty and Elizabeth Ellison
}

\title{
Investigating candidates' research experience beyond the thesis: the peripheral world of the doctorate
}

\begin{abstract}
:
This article focuses on both the process and the results of a recently completed research project that concentrated on what are commonly seen as peripheral aspects of the doctorate; that is, aspects of candidature that lie beyond, and outside of, the core work of what is widely understood to be research training. The project saw 18 candidates from the creative arts and humanities - and creative writing in particular - gather to reflect upon their learning journeys, and then analyse and theorise the 'human' dimensions of undertaking a doctorate. These often peripheral aspects were revealed to have a major influence on undertaking a research degree, as well as affecting candidates' progress and satisfaction with their studies, and career potential beyond the research degree. This article first outlines how candidates were able to develop a language with which to identify some of the major human dimensions - the lived experience - of undertaking a doctorate that emerged from the project. It then explores how candidates were able to articulate their own growth in the form of producing an edited collection of essays in order that others might benefit from this reflective learning.
\end{abstract}

\section{Biographical notes:}

Professor Donna Lee Brien is Professor of Creative Industries at Central Queensland University. She has researched and published extensively on creative writing and publishing, the creative arts, and research higher degrees, and has been a chief investigator on a number of nationally funded and other grants on the creative arts higher degree. Donna has won numerous awards for her supervision of research higher degrees, including a Vice-Chancellor's Award.

Dr Alison Owens is an adjunct Associate Professor of Education at Central Queensland University, currently at the Australian Catholic University. She has over twenty years' experience in teaching and researching education in University contexts. Alison is the recipient of multiple internal and external research grants and publishes widely on education topics. 
Professor Craig Batty is Head of Creative Writing at University of Technology Sydney, and Adjunct Professor at Central Queensland University. He is author and editor of over 70 books, chapters, journal articles and refereed conference proceedings. In 2016, he received an Australian Award for University Teaching Citation for his work supervising creative writing PhDs, and in 2017 won the RMIT Vice-Chancellor's Award for Excellence in Research Supervision.

Dr Elizabeth (Liz) Ellison is Senior Lecturer of Creative Industries at Central Queensland University. She researches Australian writing, film and television, with a special interest in the Australian beach. She has been involved in two nationally-funded grants in postgraduate supervision of creative arts research degrees, and supervises research students in creative arts and creative industries.

\section{Keywords:}

Creative writing - doctoral studies - PhD - human dimension - generic research training - peripheral skills - co-authorship 


\section{Introduction}

Although doctoral enrolments and completions have been increasing steadily in Australia (Department of Education and Training 2018a), and are now in fact weighted as responsible for half the amount of government research block grant funding ${ }^{1}$ to universities (Department of Education and Training 2018b), the quality of candidate progression and research outcomes has been interrogated and criticised (McWilliam et al. 2005). As a response, and after the release of the sector-wide Australian Council of Learned Academies review of Australia's research training system (McGagh et al. 2016), Australian universities are placing increasing pressure on doctoral candidates to complete a series of milestones and other hurdles within set timeframes. Doctoral training is becoming increasingly structured and regulated to meet these requirements. While there has been sustained interest in how to formally support doctoral candidates from enrolment to graduation (see, for instance, Evans 2011; Blaj-Ward 2011; Golovushkina and Milligan 2012; McAllister and Brien 2016; McGagh et al. 2016; Porter and Phelps 2014), little recent research on such support - which can include structured programs, coursework, industry mentoring and peer-to-peer groups - has focused on the creative arts in general, and creative writing in particular (see Batty and Sinclair 2014).

In response, as experienced research higher degree supervisors in creative writing (and the creative arts/creative practice), we were prompted to design a research project that could explore our doctoral candidates' experiences of undertaking their degree. Considering that most support which is provided to candidates usually focuses on the research process and thesis-related aspects of candidature, and post-study career opportunities, we were interested in what candidates felt they needed - or what they were provided - beyond these aspects. Here we outline the project's findings, in particular those relating to the 'human' dimensions of the doctoral journey that emerged. We discuss how, through being part of the project, candidates were able to develop a language with which to identify their challenges and issues, and - importantly - articulate their own breakthroughs and growth. We then discuss how the project has resulted in the publication of an edited collection of candidate stories and 'strategies for success', and in particular the process by which this was facilitated.

\section{Background}

Research has been conducted into how to offer support to research students over the past two decades in Australia ${ }^{2}$, including in the creative arts and creative writing. ${ }^{3}$ Reviewing these studies, however, reveals a strong focus on the content and scaffolded processes of proceeding through a research degree and writing a thesis, and on general supervision processes. What is often missing, or sidelined in footnotes, sidebars or a single chapter near the end of each study, report or volume, is the human dimension of such an undertaking - the 'lived experience' of the doctorate. Rarely, too, are candidates' views about their experience heard outside of conference proceedings or a small numbers of journals that have purposefully sought out candidates' reflections, sometimes offering new scholarly writers mentoring so that these can be published (see, for example, then-candidate Julienne van Loon's work with her supervisor Brian Dibble 
(Dibble and van Loon 2004) on the student-supervisor relationship published in TEXT, and a number of other instances).

Studies summarise the general experience of undertaking a doctorate as that of stressful anxiety (Nelson 2004; Awadh et al. 2013; Feng and Zhang 2017), and physical and emotional exhaustion (Stubb, Pyhältö and Lonka 2011; Rigg, Day and Adler 2013; Hunter and Devine 2016). Some candidates even find the experience traumatic and suffer various levels of personality and relationship breakdown (Boufis 1999; Wedemeyer-Strombel 2018). However, despite these examples, the human dimension (and the actual life circumstances of the candidate throughout their studies) are often perceived as a peripheral aspect of the doctorate. As such, they are to be dealt with by such agents as caring and perceptive supervisors, counsellors, mentors, peers and family members.

In the context of the creative arts, including in creative writing, our own experience together with anecdotal evidence suggests that $\mathrm{PhD}$ candidates' demographics present a challenge to generic research training initiatives. Our own research degree candidates often re-enter the academy after a number of years working as practitioners and/or educators in industry and/or teaching settings; many are mature-aged, with family, and other life and work commitments to negotiate; and, in contrast with candidates in other disciplines, some might not have Honours or Masters qualifications. This tallies with research that candidates may enter doctoral programs with less of a research identity than those in more traditional research disciplines (see, Finlayson 2012; Masson 2016; Wilson 2018). A core part of the research training context for these candidates, then, is the formation of a new identity: that of the practitioner-researcher. While this can be liberating and generate a whole new approach to both research and practice, it may also be an additional source of stress during the course of study. ${ }^{4}$

In most universities, these challenges can sit uncomfortably within the 'generic' research training being offered (Cater and Laurs 2014), and this is also reflected in texts provided to guide candidates through their studies. As will be discussed below, a plethora of titles have been published to support candidates (see, for instance, Leonard 2001; Denholm and Evans 2006; Wisker 2008; Green and Marshall 2010; Petre and Rugg 2010) and their supervisors (see, for instance, Denholm and Evans 2007; James and Baldwin 2006). Most of these, however, focus on achieving practical academic skills and knowledges, including in research methods and on writing the thesis. This also includes texts on the creative doctorate (Engels-Schwarzpaul and Peters 2013; Schwarzenbach and Hackett 2016), including in creative writing (Webb 2015), with these texts also largely focusing on the same important practical aspects of undertaking a doctoral degree. In this article, we outline how we worked with a number of research higher degree candidates in order to allow the often peripheral student voice to 'talk back' to such volumes.

\section{The 'Doctoral Experience' clinic}

Our project saw a group of research higher degree candidates from the creative arts and the humanities - many of whom were working in creative writing - come together to reflect upon their (lived) experiences of undertaking a doctorate, and then analyse and 
theorise those experiences. The event, which was styled as a clinic, sought to discover some of the key challenges experienced by candidates during their studies, as well as any strategies they had developed to overcome those challenges. As we have detailed in another context (Owens et al. forthcoming), we developed the event as an actionlearning experience. In doing so, it was important that, as Marquardt and Waddill suggest, the event involved 'real people resolving and taking action on real problems in real time, and learning through questioning and reflection while doing so' (2010: 186).

In line with this focus, we chose the noun 'clinic' to describe the event, working from the medical context whereby, during a clinic, outpatients are given specialist treatment or advice - and noting how the term has now been adopted for a short course on a particular subject that has a particularly practical outcome (Merriam-Webster 2019). Such clinics are particularly common in sporting and creative contexts, such as a golfing or life writing clinic. In both the medical and non-medical contexts, the clinic is a group meeting dedicated to the discussion, analysis and solution of concrete problems or the acquiring of specific skills or knowledge (Merriam-Webster 2019). We saw the event in these terms, not as pure information provision or diagnostic exercise, but rather practically focused on shared problem solving and skill attainment. An integral part of the clinic was the collaborative sharing of experience, something Mezirow and Taylor (2009) suggest promotes critical self-reflection and improved selfconfidence.

The clinic was held over two days with 18 research candidates from three universities, all of whom were then in the course of studying for, or had recently completed their studies in, a research degree in the creative arts or humanities. ${ }^{5}$ We defined this last category as graduates within three years of their graduation. The authors of this article, also from three universities (meaning that with clinic participants, five universities were represented overall), operated as facilitators and co-researchers. Participants in the clinic came from a 3,000-kilometre spread from Queensland to Victoria. This included candidates from major cities (Brisbane, Sydney, and Melbourne) and regional areas (Cairns, Mackay, Rockhampton and the Sunshine Coast, all in Queensland; and Lennox Head in New South Wales). The group was not representatively diverse in terms of Australian candidates in general, but it did include younger candidates and one male candidate among the mostly mature-aged female candidates. It also included a range of candidates from those at the very beginning of their studies, to those in the final stages before submission, and the recently completed.

Sessions included whole-of-group, moderated open discussion, and breakout working periods in which smaller groupings completed various tasks. Prior to meeting, candidates who had indicated their desire to participate were asked to consider examples of the challenges and breakthroughs they had experienced (or were experiencing) during their studies, and to come prepared to discuss these in some detail during the two days. Guided by the facilitators, candidates were then led through a series of interactive activities to identify particular and shared challenges they had experienced in undertaking their research degrees, and in the researching and producing of their theses. As candidates spoke, the facilitators used large whiteboards which lined the room to both record the data and, with the candidates' input, group the data into 
similar topics. In the funding application for this clinic, the authors - drawing on their own knowledge of doctoral degrees and experience as supervisors - suggested that these challenges would include:

specific research requirements such as designing methodology or ethical, milestone and publication issues, as well as challenges such as time management or navigating supervision and/or [university] administration ... from developing a proposal and refining a topic to responding to examination comments and postdegree publication, research and professional options. (Brien 2017)

However, it soon became apparent that what could be classed as more personal, individual, life-related concepts were emerging as key areas of struggle for candidates. These were identified as relating to three broad areas: resilience, relationships, and peer communities. While individual candidates identified their own challenges, these were added to, and drawn out, by others who had experienced similar challenges.

The focus then turned to breakthroughs, with the facilitators seeking to prompt each candidate to consider, conceptualise and share key learnings from when they had overcome a hurdle. This part of the clinic asked candidates to consider how they would describe these successes to others, by sharing positive aspects of their doctoral journey in order to not just to articulate them, but also to educate and motivate their peers to achieve what they felt they had achieved. Similar to the discussions on challenges, group discussion drew out other candidates' experiences of similar breakthroughs. These related to developing resilience, establishing and maintaining good relationships, and developing productive peer communities, but also delved deeper into these and related topics.

The facilitators moderated these discussions, listening to and probing the responses. In this way, the clinic's members conducted a group thematic analysis in-situ, which was grounded in the principles of Jennifer Attride-Stirling's thematic network analysis (2001: 388). This method employs three levels of thematic organisation, from identifying 'Basic themes' and 'Organising themes' (the latter of which we termed 'meta-themes') to finally identifying a 'Global theme'. These three levels of theme were arrived at via two main means. First, the facilitators' impressions of the underlying concepts within the relayed stories and experiences; second, the iterative verification of these concepts by the candidates. Candidates were asked to reflect upon, and discuss, what was being articulated and interpreted in this way, and were invited to contribute their own ideas and refinements. When discussing challenges, eleven meta-themes emerged. These were identified as: relationships; roles and responsibilities; the research project; dissemination; who are you?; perspective; feedback; emotion; institutional regulations and bureaucracy; personalities; and, skills. When discussing breakthroughs, eight meta-themes emerged: letting go; peer networks; research culture building; agency; thinking and organisation time; publishing/presenting; fit/flexible models; peer review; and, permission. ${ }^{6}$

Following the conclusion of the first day, with its detailed focus on challenges and breakthroughs, candidates were set a task to be completed overnight. This was to map their individual research journey, identifying both the cognitive and emotional obstacles or milestones they had experienced. This was to be recorded in written form 
on paper, although how was not prescribed. All candidates completed this task and reported back on this reflection to the group the next day. These responses were then analysed by the group (that is, by both facilitators and candidates) using a similar thematic process, which again identified themes or stages that, this time, could be roughly ordered chronologically to match the processes undertaken while completing a doctorate.

The candidates readily identified both cognitive and emotional milestones in this exercise. Emotional intelligence (Goleman 1995) was raised as an important concept in this context, both in-situ and also in the more in-depth analysis that occurred after the clinic. This has been invoked in education by Andy Hargreaves, whereby emotional intelligence is 'the capacity not only to be aware of and able to express our emotions, but to manage and moderate them effectively too' (1997: 14). In this view, the development of emotional intelligence can be a valued part of learning and teaching, as 'emotion is integral to reason and problem solving' (1997: 16). Emotional intelligence has, indeed, been found to moderate the kind of academic self-efficacy and achievement (Adeyemo 2007) required from doctoral candidates, and to even enhance creativity (Yagi et al. 2010). The candidates instinctively recognised this in the exercise. Their responses also revealed the significance of the concept of transformation, which emerged as a key aspect of doctoral study, particularly in recognition of the breakthroughs that had taken place. This idea of transformation is supported by classic research into teaching and learning, including Jack Mezirow's Transformative dimensions of adult learning (1991, 2000; see also Mezirow and Taylor 2009). Mezirow identifies transformation as one of the foundational dimensions of adult learning, whereby such learners reflectively transform their 'beliefs, attitudes, opinions, and emotional reactions' (1991: 223). In Michael Prosser and Keith Trigwell's discussion of conceptual change and deep learning, postgraduate-level learning provides a means of developing 'personal meaning through a paradigm shift in ... world view' (1999: 149). For the candidates in this project, their conceptual world-view transformations had both cognitive (learning) and emotional (personal) qualities.

The idea of the journey as a metaphor for undertaking a doctoral degree was also raised early in the clinic, and was repeated often. This metaphor soon became a shared way for candidates to discuss their doctoral experiences, and a concept that could encompass their motivations, learning and personal transformations, processes, and relationships. For instance, candidates discussed the importance of understanding research skill development as an ongoing 'process', rather than a 'problem' for which there is a single, identifiable solution. They also spoke of the necessity of 'taking others on the journey with you', rather than alienating support networks while deep in their studies. At one stage, the group agreed that these ideas of passage and procedure were particularly relevant to them in the creative arts disciplines, and in creative writing, where the journey and process itself is an integral and explicit part of many projects.

Transformation and 'the hero's journey' - the latter gleaned from Joseph Campbell's 1949 concept of 'the hero's journey' (1993) - was thus identified as, and agreed upon to be, the global theme. In another article by the authors (Batty et al. 2019), we have examined this aspect specifically and have offered a mapping of what we termed 'the doctoral hero'. The clinic discussions reported on in that article clearly log the 
emotional, psychological and physical, as well as the intellectual, components of an individual's lived experience of a four-year (or longer) engagement in higher degree by research study.

The strongly emotional aspects of the findings of our study resonate with theories of adult learning as a space in which the cognitively complex, contingent and contested is performed. Disorientation (Mezirow 2000), and delay and retreat (Perry 1975) are some possible responses to the questioning of deeply held assumptions commonly experienced by doctoral candidates. Other studies have also identified problematic mental health outcomes for doctoral candidates (Toews et al. 1997; Hyun et al. 2006; Barry et al. 2018), and this is also a concern for academics (Krause 2018). In response, some have advocated formal support (such as counselling), informal support (such as self-care strategies), and team-based support (especially in doctoral writing) (Barry et al. 2018). It has not been suggested, however, that these initiatives should be core to research training and/or research training programs.

\section{Co-authoring the research findings}

Our global theme of 'transformation and the hero's journey' was then used as the basis for developing candidate-authored essays for an edited book. A publication about common research degree candidate challenges and breakthroughs was always envisaged as a possible outcome of the project, but its specific focus, rationale and content emerged from the clinic. As such, during the second half of the second day the participants discussed and mapped the themes and ideas that had emerged up until that point, and collaboratively came up with a chapter topic and outline for each candidate based on their (and others') key challenges, breakthroughs and other insights. These chapters were then grouped into broader book sections, and their authors put into writing groups reflecting these sections.

The facilitators discussed openly that we wanted to produce a book that was different to those already in the market; one that would reflect the authentic content that emerged through the clinic, and, importantly, that would include the student voice. Of the large number of texts claiming to assist candidates in enduring the period of their research degree, it is significant how many include the words 'survive', 'surviving' or 'survival' in their titles. Following the early example of Leonie Elphinstone and Robert Schweitzer's How to get a research degree: a survival guide (1998), other volumes include those by Jason R. Karp (2009), Suzan Burton and Peter Steane (2010), Adam Ruben (2010), Patricia Gosling and Bart Noordam (2010), Michael Fennell (2013), David Sternberg (2014), Lene Tanggaard and Charlotte Wegener (2016) and, most recently, Christopher McMaster, Caterina Murphy, Benjamin Whitburn and Inger Mewburn's Postgraduate study in Australia: surviving and succeeding (2017). There are also specialist texts that use this rhetorical device in their titles in volumes focused on specific disciplines (Turner, Jeter-Twilley and Malinajdovska 2010), geographical locations (McMaster, Murphy and de Lasson 2017) and study modes (Deveaux et al. 2010). Alongside these 'survival' guides there is even a publication that suggests completing a doctoral degree is akin to surviving a war: George W. Rideout's Ph.D. War stories: real people $\sim$ real stories $\sim$ real success (2012). These and other such texts 
support a range of scholarship which acknowledges that doctoral study is a cognitive and emotional battle for candidates - but in all of them, the human dimension of undertaking such a degree and the voices of candidates is not central or foregrounded. This is what we felt strongly about providing in our book, especially given the methodology for how the content came into being.

After the clinic, each candidate was tasked with developing their individual chapter over a period of three months. As a component of this development, the writing groups worked together by email and videoconference to ensure that the material identified and discussed in each chapter was thematically aligned, complementary, and not repetitive. They also worked to supply critique and support to each other in terms of the writing process. Once a full first draft of each chapter was completed, candidates then worked in pairs to refine and closely edit each draft. This approach speaks to work by Claire Aitchison (2009; and Aitchison and Guerin 2014) on research writing groups for doctoral candidates, in which candidates learn to write through actions of, and beyond, writing (for example, sharing and receiving feedback, engaging in discussion about the writing, and so on). The finished first drafts were then workshopped within the section group, refined and edited again by the pairs, and then submitted to the editors. The facilitators, by then the volume's editors, read all chapters and provided consolidated feedback on each chapter. Each candidate then worked again with their group members to respond to the editors' comments and produce a refined second draft. Once second drafts were complete, the editors arranged these into an order which, in some cases, meant that the volume's sections, and their contents, differed slightly from that proposed at the workshop. With this new order in hand, the editors then also proposed some edits and, at times, minor changes and additions to each chapter.

In developing each chapter and section of the volume, the global theme of 'transformation and the hero's journey' was used as an overarching guide. This helped candidates focus on their chapter and its contents. Once the second draft chapters were complete, however, it was clear that the elaboration of the journey metaphor in each chapter, and in most of the chapter titles, read as a little heavy-handed. In response, the editors suggested slight final alterations to each chapter, the order of the book, and the title. The aim in this - as discussed with, and agreed to by, candidates when planning the volume at the clinic - was to produce more than just a collection of essays on the topic of doctoral study. Authors and editors, instead, worked closely together to ensure the book could also be read as a single volume - with a consistent style and approach although the uniqueness of each candidate's voice was maintained in their individual chapter. What emerged strongly in this final draft was the recurring focus on the emotional and psychological resilience needed to undertake and complete a doctoral degree. One of the anonymous book reviewers noted this and its value, stating: 'The strong focus on self-care and mental health, issues that have not been emphasized in the past books are valuable additions to the field and address ... new areas'.

The editorial team then wrote an introduction to the volume, and introductions to each of the book's five sections. In these editorial essays, we endeavoured to add contextual educational and theoretical framing to the chapters, but without offering an exegeticaltype 'explanation' for them, which would have - we believed - diminished the sense of validity offered by the candidates' voices. Due to its projected dual student and 
supervisor audience, this research- and experience-based supervisor-candidate nexus is, we feel, a critical feature of the book. However, just like exemplary supervision, rather than intervene and take over the project, we believe that as supervisor-editors, our writing sits alongside that of the candidates, and adds additional support to their ideas and experiences.

\section{The Doctoral experience volume}

Now in the final stages of publication, The doctoral experience: student stories from the creative arts and humanities (Brien et al. in press) has been developed and written to be a book that offers both personal and professional insights into the challenging yet rewarding journey of undertaking a doctorate. Written predominantly by candidates, its intended audience is proposed as current research higher degree candidates and their supervisors. Unlike the other many useful books described above that focus on the knowledge, skills, thesis research and writing, and degree milestones that completing doctoral level study entails, this book is organised around the themes and concerns that a series of candidates have themselves identified as centrally important to successfully completing a research higher degree. From assessing the self's readiness for doctoral study - in terms of personal resources, knowledges and skills - to working with others, building resilience, developing networks, and considerations of how ethical conduct permeates a researcher's practice, the collection includes personal perspectives and case studies. For many of these candidates, this was their first chapter in a scholarly book and for almost all, the first in a publication with an international publisher (the Palgrave Macmillan imprint, now produced by global publishers, Springer).

\section{Conclusion}

The Australian Qualifications Framework (AQF) defines doctoral level graduates as possessing: 'systematic and critical understanding of a complex field of learning and specialised research skills' (AQF Council 2013: 18). Near the end of the four-page elaboration of the Australian Government's expectations of doctoral level learning, there is also a note that doctoral graduates will also possess generic graduate attributes falling into 'four broad categories: fundamental skills; people skills; thinking skills; and personal skills'. There are no further details of these various skills, the framework noting that they are 'defined by each higher education provider' (65). Many of these generic (or peripheral) skills, we believe, are demonstrated by these candidates and graduates in their contributions to The doctoral experience volume.

Over the course of the intensive two days spent with candidates, and then during the close working relationship engendered over the 17-month period from the clinic until the manuscript was delivered to the publisher, a wealth of information and reflection on the doctoral candidate experience emerged. Much of this is encapsulated in the book, while as supervisors and editors, we have ruminated on what emerged from the clinic and ensuing processes in a number of presentations and publications (see Batty et al. 2019; Owens et al. in press). We want to conclude here, however, by underscoring how key it was, in this work, to authentically embrace the candidates' individual voices. 
Although the candidate is, obviously, the focus of doctoral programs and supervision, the candidate's voice can be seen to have been largely peripheral to discussions of training provision, except in the candidate-supervisor relationship. We, therefore, through all parts of the project - from recruitment to manuscript delivery - had to find ways to encourage each of the candidates to speak up and contribute thoughtfully, then to reflect upon and analyse what they heard from each other. A key aim of the project, which we believe was achieved, was to assist and empower candidates to develop a language with which to identify their challenges and issues, and - importantly - to articulate their own breakthroughs and growth, so that both they and others might also benefit from this learning.

Encouragingly, the anonymous book proposal reviewers commented on the freshness of this approach and the importance of hearing the candidates' voices in this context. One of these reviewers noted 'the student voices' as a major strength of the volume, continuing:

There are some unique perspectives here ... the unique student voices, which is a real selling point of the proposal. ... I always appreciate hearing from the students themselves ... The fact that much of the book is written by current or recent doctoral students is original. Compared to other resources on doctoral education, this approach is not common ... a "new/emerging" approach to understanding doctoral education.

Another reviewer listed as a strength the 'chapters that are the voices of doctoral candidates who are adults with extensive professional experience who write about their personal insights with (sic) the doctoral journey'.

In this, and the project as a whole, the notion of the individual, human and emotional dimensions thus emerged as core, rather than peripheral, aspects of undertaking a doctoral-level degree. These hitherto peripheral aspects were, however, revealed to have a major influence on the experience of undertaking a research degree, as well as affecting candidates' progress and their satisfaction with their studies. In embracing the candidate voice, this project and its outcomes suggests that a more holistic approach to research training can, and would, yield dividends not only to the candidate, but also to supervisors, institutions and the discipline at large.

The emphasis on relationships with others (interpersonal) and with the self (intrapersonal/self-care) that was evident from the candidates' oral and written commentary provides evidence of the central importance of what could be classed 'people skills' and 'personal skills' (AQF) to those undertaking a doctorate. Focusing on the human dimensions of doctoral study and supporting the development of emotional intelligence and resilience through the kind of collaborative training described herein can arguably engender 'transformation' rather than 'survival' for candidates, and in the process provide a much more empowering doctoral experience.

\section{Endnotes}

1. Research block grant funding is that funding which comes to universities to support continued research activity and research growth, including research training (for example, the provision of tuition fee waivers for all domestic candidates, and living allowance stipends for some of these). 
2. This includes the in-depth studies funded by the now-disestablished government-funded Office of Learning and Teaching, which funded the projects below. These can be categorised into the following topic areas: pedagogies of supervision (Bruce et al. 2009; Hammond et al. 2010; Harrison 2014); supervision standards and quality (Baker et al. 2009); supervision support (Blass et al. 2014; Hamilton et al. 2014; Homewood et al. 2010; Maor and Fraser 2015; Yarlagadda et al. 2013); doctoral candidates' academic history (Boud et al. 2014; Kiley 2011; Kiley 2013; Kiley, Bell and Feng 2013); specific discipline support (Colbran and Tynan 2008; Webb and Brien 2008); support appropriate to cross-cultural contexts (Homewood et al. 2010); and, thesis assessment/examination (Phillips, Stock and Vincs 2009; Webb and Brien 2012).

3. Those focusing specifically on creative writing include Webb and Brien $(2008 ; 2012)$.

4. The online Australian Postgraduate Writers Network, established in 2007, set up to provide a national forum for knowledge development and transfer, recognised such differences. Funded by the Australian Learning and Teaching Council to 'ameliorate the challenges of creative writing research training' nationally (Webb and Brien 2008), research for this project identified candidates' feelings of isolation and the human dimension of completing a research higher degree.

5. See also, for more on the project methodology, Batty et al. (2019) and Owens et al. (in press).

6. These meta-themes, and the basic themes that inform them, are discussed in more detail in the authors' related article 'Mapping the emotional journey of the doctoral "hero": challenges faced and breakthroughs made by creative arts and humanities candidates' (Batty et al. 2019).

\section{Works cited}

Adeyemo DA 2007 'Moderating influence of emotional intelligence on the link between academic selfefficacy and achievement of university students' Psychology and developing societies, 19 (2), 199-213

Aitchison, Claire 2009 'Writing groups for doctoral education' Studies in higher education, 34 (8), 905-16

Aitchison, Claire and Cally Guerin 2014 Writing groups for doctoral education and beyond: innovations in practice and theory London: Routledge

Attride-Stirling, Jennifer 2001 'Thematic networks: an analytic tool for qualitative research' Qualitative research 1 (3), 385-405

Australian Qualifications Framework Council 2013 Australian qualifications framework $2^{\text {nd }}$ ed, Adelaide: Australian Qualifications Framework Council and Australian Government

Awadh, Ammar Ihsan, Noorizan Abdul Aziz, Saramd Nabhan Yaseen, Shaymaa Abdalwahed Abdulameer, Mohanad Naji Sahib and Omer Qutaiba B Al-Lela 2013 'A comparison study of perceived stress and quality of life among Master of Pharmacy and non-pharmacy Master's students' Pharmacy education 13 (1), 22-28

Baker, Su and Brad Buckley 2009 Future-proofing the creative arts in higher education: scoping for quality in tertiary creative arts learning, teaching, and research training Project final report, Sydney: Australian Teaching and Learning Council, at https://ltr.edu.au/resources/DS7624\%20Creative\%20Arts\%20Baker\%20Melbourne\%202009\%20report.pdf (accessed 29 March 2019)

Barry, Karen, Megan Woods, E Warnecke, Christine Stirling and Angela Martin 2018 'Psychological health of doctoral candidates: study-related challenges and perceived performance' HERDSA 37 (3), 468-83

Batty, Craig, Elizabeth Ellison, Alison Owens and Donna Lee Brien 2019 'Mapping the emotional journey of the doctoral "hero": challenges faced and breakthroughs made by creative arts and humanities candidates' Arts and humanities in higher education, at https://doi.org/10.1177/1474022219844986 (accessed 14 July 2019) 
Batty, Craig and Jennifer Sinclair 2014 'Peer-to-peer learning in the higher degree by research context: a creative writing case study' New writing: the international journal for the practice and theory of creative writing, 11 (3), 335-46

Blaj-Ward, Lia 2011 'Skills versus pedagogy?: doctoral research training in the UK arts and humanities' Higher education research \& development 30 (6), 697-708

Blass Eddie, Santina Bertone, Joe Luca, Craig Standing, Ron Adams, Helen Borland and Qing-Long Han 2014 Developing a toolkit and framework to support new postgraduate research supervisors in emerging research areas, at https://ltr.edu.au/resources/ID11_2091_Blass_report_2013.pdf (accessed 29 March 2019)

Boud David, Angela Brew, Robyn Dowling, Margaret Kiley, Janne Malfroy, Jo McKenzie, Nicky Solomon and Kevin Ryland 2014 Building local leadership for research education, at https://tr.edu.au/resources/LE11_1982_Boud_Report_2014.pdf (accessed 29 March 2019)

Boufis, Christina 1999 'Strange bedfellows: does academic life lead to divorce?' Salon 25 March, at https://www.salon.com/1999/03/25/24feature_5 (accessed 29 March 2019)

Brien, Donna Lee, Craig Batty, Elizabeth Ellison and Alison Owens (eds) in press The doctoral experience: student stories from the creative arts and humanities Basingstoke: Palgrave Macmillan

Brien, Donna Lee 2017 'Research (training) textbook: empowering candidates to think, work and produce independently' School of Education and the Arts Research Grant, Noosa: CQUniversity Australia

Bruce, Christine, John Bell, Susan Gasson, Shlomo Geva, Kerry Kruger, Catherine Manathunga, Kunle Oloyede, Peter O'Shea, Ian Stoodley, Kerry Raymond and Rod Wissler 2009 Towards a pedagogy of supervision in the technology disciplines, at https://tr.edu.au/resources/Bruce\%2C\%20C\%20ALTC\%20Fellowship\%20report\%202009.pdf (accessed 29 March 2019)

Burton, Suzan and Peter Steane (eds) 2010 Surviving your thesis New York: Routledge

Campbell, Joseph 1993 The hero with a thousand faces London: Fontana. 1st pub. 1949

Cater, Susan and Deborah Laurs (eds) 2014 Developing generic support for doctoral students: practice and pedagogy London: Routledge

Colbran, Stephen and Belinda Tynan 2008 Australian law postgraduate network (ALPN), at https://tr.edu.au/resources/grants_le_project_report_alpn_feb09.pdf (accessed 29 March 2019)

Denholm, Carey and Terry Evans (eds) 2006 Doctorates downunder: keys to successful doctoral studying Australia and New Zealand Adelaide: ACER Press

Denholm, Carey and Terry Evans (eds) 2007 Doctorates downunder: keys to effective supervision in Australia and New Zealand Adelaide: ACER Press

Department of Education and Training 2018a Higher education statistics data cube (ucube): enrolment count by mode of attendance by type of attendance by gender by course level by field of education, at http://highereducationstatistics.education.gov.au (accessed 29 March 2019)

Department of Education and Training 2018b Research block grants - a snapshot, at https://docs.education.gov.au/documents/research-block-grants-snapshot (accessed 29 March 2019)

Deveaux, Sybil M, Andy Elliot, Leilani Longa, Melanie Magruder, Cheryl Szyarto, Ed S Turner III 2010 Full speed ahead: surviving to thriving as an online doctoral student Phoenix: Doctors Publishing Group

Dibble, Brian and Julienne van Loon 2004 'The higher degree research journey as a three-legged race' TEXT: the journal of the Australian Association of Writing Programs 8 (2), at http://www.textjournal.com.au/oct04/dibble_vanloon.htm (accessed 30 June 2018)

Elphinstone, Leonie and Robert Schweitzer 1998 How to get a research degree: a survival guide St. Leonards: Allen \& Unwin

Engels-Schwarzpaul, A-C and MA Peters (eds) 2013 Of other thoughts: non-traditional ways to the 
doctorate: a guidebook for candidates and supervisors Rotterdam: Sense Publishers

Evans, Linda 2011 'The scholarship of researcher development: mapping the terrain and pushing back boundaries' International journal for researcher development 2, 75-98

Feng, Rong and Yantong Zhang 2017 'A study on influential factors to psychological anxiety of doctoral students at school based on grounded theory' Journal of graduate education 3, at http://en.cnki.com.cn/Article_en/CJFDTotal-JIAO201703009.htm (accessed 30 June 2018)

Fennell, Michael 2013 Surviving the PhD Whitley Bay: Consilience Media

Finlayson, Katrina 2012 'Encounters with future selves: crafting an identity as a creative-writing academic' in Encounters: place, situation, context - the refereed proceedings of the 17th conference of the Australasian Association of Writing Programs AAWP, 1-9

Goleman, Daniel 1995 Emotional intelligence New York: Bantam

Golovushkina, Elena and Colin Milligan 2012 'Developing early stage researchers' International journal for researcher development 3, 64-78

Gosling, Patricia and Bart Noordam 2010 Mastering your PhD: survival and success in the doctoral years and beyond Berlin: Springer-Verlag

Green, Nick and Stephen Marshall 2010 Your PhD companion: the insider guide to mastering the practical realities of getting your $P h D 3^{\text {rd }}$ edition, Oxford: How To Books

Hamilton, Jillian, Mandy Thomas, Susan Carson and Elizabeth Ellison 2014 Good practice report: postgraduate research and coursework degrees, at https://tr.edu.au/resources/SP13_3265_Final_Hamilton_2013.pdf (accessed 29 March 2019)

Hammond, Jennifer, Kevin Ryland, Mark Tennant and David Boud 2010 Building research supervision and training across Australian universities, at http://dro.deakin.edu.au/eserv/DU:30071948/boud-buildingsupervisory-2010.pdf (accessed 29 March 2019)

Hargreaves, Andy (ed) 1997 Rethinking educational change with heart and mind Alexandria: Association for Supervision and Curriculum Development

Harrison, Scott 2014 Pro-active music higher degrees: promoting, acting on and evaluating quality teaching and learning in music higher degrees, at https://ltr.edu.au/resources/Harrison_S_NTF_Report_2014.pdf (accessed 29 March 2019)

Homewood, Judi, Theresa Winchester-Seeto, Jacqueline Mackaway and Christa Jacenyik-Trawoger 2010 Development and evaluation of resources to enhance skills in higher degree research supervision in a cross-cultural context, at https://ltr.edu.au/resources/CG7507\%20Macquarie\%20Homewood\%20Final\%20Report\%202010.pdf (accessed 29 March 2019)

Hunter, Karen H and Kay Devine 2016 'Doctoral students' emotional exhaustion and intentions to leave academia' International journal of doctoral studies 11, 35-61

Hyun, Jenny K, Brian C Quinn, Temina Madon and Steve Lustig 2006 'Graduate student mental health: needs assessment and utilization of counseling services' Journal of college student development 47 (3), 247-66

James, Richard and Gabrielle Baldwin 2006 Eleven practices of effective postgraduate research supervisors University of Melbourne: School of Graduate Studies

Karp, Jason R 2009 How to survive your PhD: the insider's guide to avoiding mistakes, choosing the right program, working with professors, and just how a person actually writes a 200-page paper Naperville, Ill: Sourcebooks

Kiley, Margaret 2013 I've done a coursework masters now I'd like to do a doctorate: can I?, at http://courseworkmasters.anu.edu.au/dissemination.htm (accessed 29 March 2019)

Kiley, Margaret 2011 Where are our doctoral candidates coming from and why?, at https://ltr.edu.au/resources/SI10_1889_Kiley_Report_2011.pdf (accessed 29 March 2019) 
Kiley, Margaret, Karen Bell and Lingbing Feng 2013 Report of the online surveys related to OLTfunded project: 'Coursework in Australian doctoral education: what's happening, why, and future directions?, at http://chelt.anu.edu.au/sites/default/files/20131113combined\%20survey\%20report\%20final.pdf (accessed 29 March 2019)

Krause, Grace 2018 'We must confront the culture of overwork to tackle academia's mental health crisis', Times higher education 14 June, at https://www.timeshighereducation.com/blog/we-mustconfront-culture-overwork-tackle-academias-mental-health-crisis (accessed 29 March 2019)

Leonard, Diana 2001 A women's guide to doctoral studies Buckingham: Open University

Maor, Dorit and Barry Fraser 2015 Design of a participatory supervision support platform for improving higher degree supervision: a feasibility study, at https://tr.edu.au/resources/SD12_2447_Maor_Report_2015_0.pdf (accessed 29 March 2019)

Marquardt, Michael and Deborah Waddill 2010 'The power of learning in action learning: a conceptual analysis of how the five schools of adult learning theories are incorporated within the practice of action learning' Action learning: research and practice 1 (2), 185-202

Masson, Sophie 2016 'Breaking the pattern: established writers undertaking creative writing doctorates in Australia', TEXT: journal of writing and writing courses 20 (2), at http://www.textjournal.com.au/oct16/masson.htm (accessed 29 March 2019)

McAllister, Margaret and Donna Lee Brien 2016 Delivering effective interdisciplinary doctoral academic research training (IDART) across nursing and creative arts Scholarship of Learning and Teaching Grant, Noosa: Central Queensland University

McGagh, John, Helene Marsh, Mark Western, Peter Thomas, Andrew Hastings, Milla Mihailova and Matt Wenham 2016 Review of Australia's research training system: report for the Australian Council of Learned Academies, at http://www.acola.org.au (accessed 29 March 2019)

McMaster, Christopher, Caterina Murphy, Benjamin Whitburn and Inger Mewburn (eds) 2017

Postgraduate study in Australia: surviving and succeeding new ed, New York: Peter Lang

McMaster, Christopher, Caterina Murphy and Jakob Rosenkrantz de Lasson (eds) 2017 The Nordic PhD: surviving and succeeding New York: Peter Lang

McWilliam, Erica, Alan Lawson, Terry Evans and Peter Taylor 2005 'Silly, soft and otherwise suspect: doctoral education as risky business' Australian journal of education 49 (2), 214-27

Merriam-Webster Dictionary 2019 'Clinic', Merriam-Webster dictionary, at https://www.merriamwebster.com/dictionary/clinic (accessed 29 March 2019)

Mezirow, Jack 1991 Transformative dimensions of adult learning San Francisco: Jossey-Bass Publishers

Mezirow, Jack 2000 Learning as transformation: critical perspectives on a theory in progress San Francisco: Jossey-Bass Higher and Adult Education Series

Mezirow, Jack and Edward W Taylor 2009 Transformative learning in practice: insights from community, workplace and higher education, Hoboken, NJ: John Wiley \& Sons

Nelson, Robert 2004 'Doctoralness in the balance: the agonies of scholarly writing in studio research degrees' TEXT: the journal of the Australian Association of Writing Programs Special issue 3, April, at http://www.textjournal.com.au/speciss/issue3/nelson.htm (accessed 29 March 2019)

Owens, Alison, Elizabeth Ellison, Donna Lee Brien and Craig Batty in press 'Agency and ownership in doctoral learning: student reflections on the transformative research journey' Studies in graduate and postdoctoral education

Perry, William G 1975 'Intellectual and ethical development in the college years' in Noel Entwistle and Dai Hounsell (eds), How students learn, University of Lancaster, UK: Institute for Research and Development in Post-Compulsory Education, 139-49

Petre, Marian and Gordon Rugg 2010 The unwritten rules of PhD research $2^{\text {nd }}$ ed, Maidenhead: Open University Press 
Phillips, Maggi, Cheryl Stock and Kim Vincs 2009 Dancing between diversity and consistency: evaluating assessment in postgraduate studies in dance, at https://tr.edu.au/resources/grants-ppdancing-ecu-booklet-2009_0.pdf (accessed 29 March 2019)

Porter, Susan D and Jennifer M Phelps 2014 'Beyond skills: an integrative approach to doctoral student preparation for diverse careers' Canadian journal of higher education 44 (3), 54-67

Prosser, Michael and Keith Trigwell 1999 Understanding learning and teaching: the experience in higher education Buckingham UK: The Society for Research into Higher Education and Open University Press

Rideout, George W (ed) 2012 PhD war stories: real people $\sim$ real stories $\sim$ real success Southaven: Evolution Strategists Press

Rigg, Julaine, Jonathon Day and Howard Adler 2013 'Emotional exhaustion in graduate students: the role of engagement, self-efficacy, and social support' Journal of educational and developmental psychology 3 (2), 138-52

Ruben, Adam 2010 Surviving your stupid, stupid decision to go to grad school New York: Three Rivers Press

Schwarzenbach, Jessica and Paul Hackett 2016 Transatlantic reflections on the practice-based PhD in fine art New York: Routledge

Sternberg, David 2014 How to complete and survive a doctoral dissertation New York: St Martin's Griffin

Stubb, J, K Pyhältö and K Lonka 2011 'Balancing between inspiration and exhaustion: PhD students' experienced socio-psychological well-being' Studies in continuing education 33 (1), 33-50

Tanggaard, Lene and Charlotte Wegener 2016 A survival kit for doctoral students and their supervisors: traveling the landscape of research Thousand Oaks: SAGE

Toews, John A, Jocelyn M Lockyer, Deborah JG Dobson, Elizabeth Simpson, A Keith W Brownell, Fraser Brenneis, Kathleen M MacPherson and Gerard S Cohen 1997 'Analysis of stress levels among medical students, resident, and graduate students at four Canadian schools of medicine' Academic medicine 72 (11), 997-1002

Turner, J Fidel, Rhonda Jeter-Twilley and Ljubica Malinajdovska (eds) 2010 Selecting and surviving $a$ doctoral program in counseling: strategies for success and completion San Diego: University Readers

Webb, Jen 2015 The creative doctorate Newmarket: Frontinus

Webb, Jen and Donna Lee Brien 2008 Australian writing programs network (CG642): final report prepared for the Australian Learning and Teaching Council, at https://tr.edu.au/resources/CG642_UC_Webb_Final\%20Report_Feb09.pdf (accessed 29 March 2019)

Webb, Jen and Donna Lee Brien 2012 Examining doctorates in the creative arts: a guide Canberra: Australasian Association of Writing Programs

Wedemeyer-Strombel, Kathryn R 2018 'Why does graduate school kill so many marriages?'

ChronicleVitae 17 October, at https://chroniclevitae.com/news/2118-why-does-graduate-school-kill-somany-marriages (accessed 29 March 2019)

Wilson, Jenny 2018 Artists in the university: positioning artistic research in higher education Singapore: Springer

Wisker, Gina 2008 The postgraduate research handbook: succeed with your MA, MPhil, EdD and PhD $2^{\text {nd }}$ ed, Basingstoke: Palgrave Macmillan

Yagi, T, T Sugio, M Yogo, K Akama and K Azuma, K 2010 'The role of art in a creative economy: testing the relationship between emotional intelligence and creativity', in 16th international conference on cultural economics 9-12 June, Copenhagen: Association for Cultural Economics International, at http://www.acei2010.com (accessed 29 March 2019)

Yarlagadda Prasad KDV, Karen Woodman, Pujitha Silva, Acram Taji, Tony Sahama, James Trevelyan Shamim Samani, Hema Sharda, Ramesh Narayanaswamy and Anthony Lucey 2013 A model for 
research supervision of international students in engineering and information technology disciplines, at https://tr.edu.au/resources/PP10-1771_Yarlagadda_Report_2013.pdf (accessed 29 March 2019) 